\title{
Efficiency analysis of an induction motor with field- oriented control at a hot rolling mill
}

\begin{abstract}
Rupert Gouws
Faculty of Engineering, School of Electrical, Electronic and Computer Engineering, North-West University, Potchefstroom, 2520, South Africa. E-mail: Rupert.Gouws@nwu.ac.za. Tel: +27 18299 1902. Fax: +27 182991977.

Accepted 23 July, 2012

In this paper, the efficiency analysis of an induction motor with field-oriented control (FOC) at a hot rolling mill in South Africa is presented. It is shown that the energy consumption of an induction motor at a hot rolling mill can be improved with the introduction of FOC with a variable input reference compared to direct torque and flux control (DTC) with a fixed input reference. An overview on the control process of the induction motor with FOC and the schematics of the field-oriented controller are presented. Results for the following two scenarios are presented: 1) the induction motor is controlled at a constant speed with a variable thickness slab by means of DTC and 2) the induction motor is controlled according to the thickness of the slab by means of FOC. Overall results obtained showed an average improvement of $3.67 \%$ in the energy consumption of the experimental test setup system from scenario 1 to scenario 2. The simulation and experimental results that illustrate the performances of the proposed scenarios are also presented.
\end{abstract}

Key words: Induction motor, field-oriented control, hot rolling mill, energy efficiency.

\section{INTRODUCTION}

It is estimated that globally around $40 \%$ of the electricity supplied to the industrial sector is consumed by electric motorised systems and for South Africa induction machines in the industrial sector consume around $60 \%$ of the electricity supplied (DME, 1998). It is therefore important to invest in projects to lower the energy consumption (or improve the efficiency) of specifically induction machines, which is also the motivation for this project.

In this paper, the efficiency analysis of an induction motor with field-oriented control (FOC) at a hot rolling mill in South Africa is presented. It is shown that the energy consumption of an induction motor at a hot rolling mill can be improved with the introduction of FOC with a variable input reference compared to direct torque and flux control (DTC) with a fixed input reference, which is also the contribution of this project.

Gouws (2011) provide the analysis of an induction motor with DTC at a hot rolling mill in South Africa and emphasize that other control techniques might provide better results in terms of energy consumption (and energy efficiency). The results obtained from DTC with a fixed input reference were sufficient, but did not provide the optimum result in terms of energy consumption (and energy efficiency) at a hot rolling mill in South Africa.

Various other control techniques were therefore investigated of which one of them were FOC. This article therefore compares the performance and energy consumption of the direct torque and flux controller with the field-oriented controller at a hot rolling mill in South Africa.

Efficiency analysis for the following two scenarios are presented: 1) where the speed of the induction motor is kept constant with a variable thickness slab (original condition with DTC) and 2) where the speed of the induction motor is controlled according to the thickness of the slab (improved condition with FOC).

\section{MATERIALS AND METHODS}

This section provides an overview of hot rolling mill plant and the control process for the induction motor. 


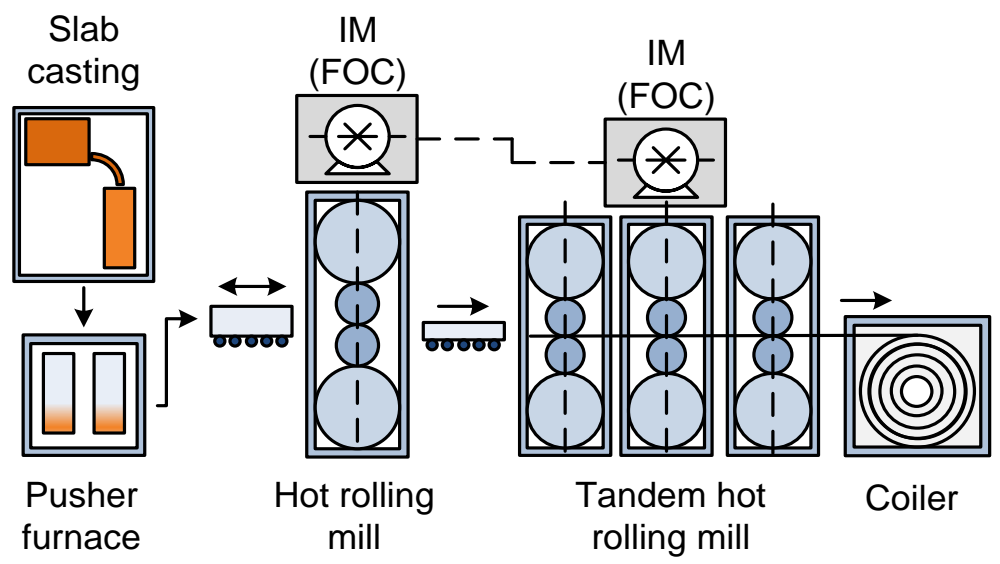

Figure 1. Hot strip/rolling production process for an induction motor with fieldoriented control (FOC).

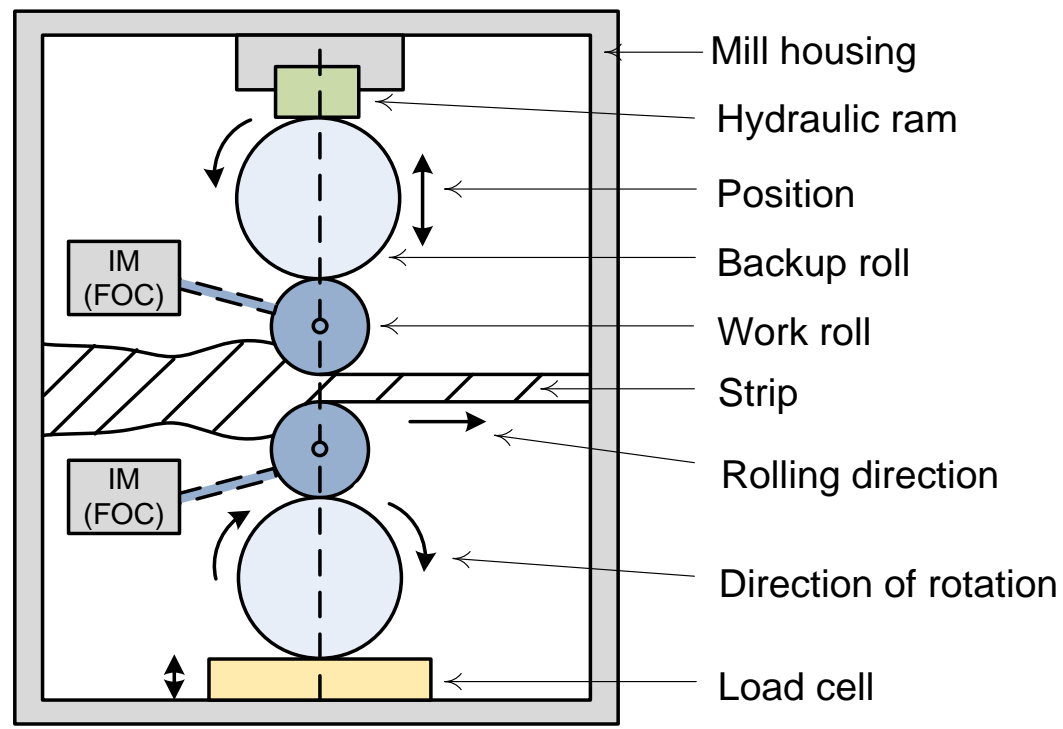

Figure 2. Four-high hot rolling mill stand for the induction motor with field-oriented control.

\section{Hot rolling mill plant}

A hot rolling mill plant near Witbank (in Mpumalanga, South Africa) was used as a case study for this project. Gouws (2011) provide more detail on the specification and parameters, together with an overview of this specific hot rolling mill plant.

Figure 1 provides an overview diagram of the hot rolling mill production process for an induction motor with FOC. After the slab casting process (the refining and alloying processes), the molten metal is cast into semi-continuous casters of 10 to 25 ton slabs (Achenbach, 2002). The slabs are then pre-heated in the pusher furnace and hot rolled by a single-stand hot rolling mill which are then passed through a tandem hot rolling mill, which provides strips with a thickness of 2.5 to $6 \mathrm{~mm}$. The strips are then coiled at a temperature of approximately $300^{\circ} \mathrm{C}$ (Achenbach, 2002). The induction motor with FOC is connected to the shaft of the work roller, as shown in Figures 1 and 2. Lenard (2007) provides more detail on the flat rolling process in the metal industry.

Figure 2 provides an overview diagram of the four-high hot rolling mill stand for the induction motor with FOC. Two work rollers reduce the thickness of the slab into a strip.

A high compression force applied by hydraulic rams causes the reduction in thickness. The reduction in strip thickness causes a temperature rise at the roll gap, which is cooled by air and a lubricant solution (Pittner and Simaan, 2011).

Hot rolling mills are usually equipped with sensors to measure the roll force at each stand, strip tension force, strip thickness, work roll speed, roll gap actuator (hydraulic ram) position and strip speed (Pittner and Simaan, 2011).

The backup rolls are installed to provide rigid support to the working rolls and to prevent bending under rolling load (Pittner and Simaan, 2011). The induction motor with FOC is connected to 
Table 1. Hot strip/rolling mill plant parameters.

\begin{tabular}{lc}
\hline Parameter & Dimension \\
\hline Work roll diameter & $505 \mathrm{~mm}$ \\
Backup roll diameter & $1265 \mathrm{~mm}$ \\
Asynchronous motor & $110 \mathrm{~kW}$ \\
Rolling force & $30,000 \mathrm{kN}$ \\
Rolling torque & $2500 \mathrm{kNm}$ \\
Roll barrel length & $2500 \mathrm{~mm}$ \\
Work roll axial shift stroke & $100 \mathrm{~mm}$ \\
\hline
\end{tabular}

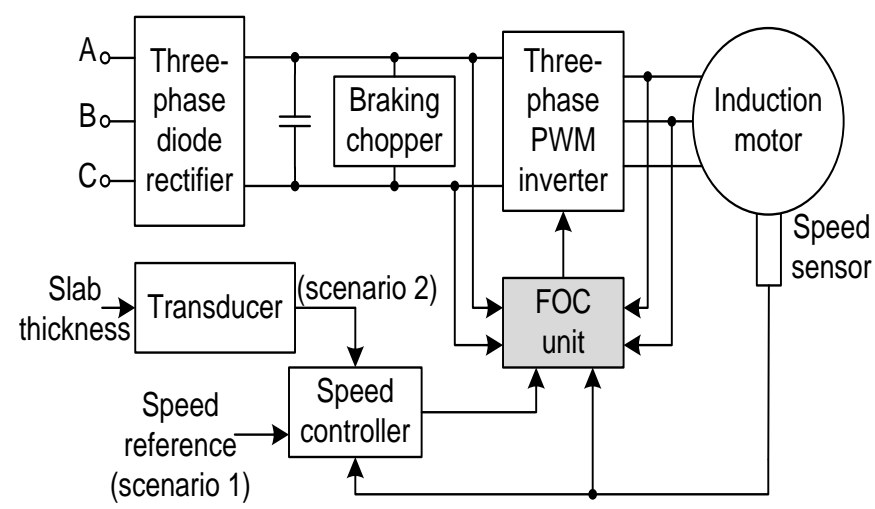

Figure 3. Overview on the control process for the induction motor with field-oriented control.

the work roller of the hot rolling mill stand as shown in Figure 2.

Islam (2010) and Kubota (1994) provide more detail on FOC for interior permanent magnetic synchronous motors (IPMSM) and speed sensor-less FOC of an induction motor with rotor resistance adaptation.

Table 1 provides the parameters of the hot rolling mill plant near Witbank (in Mpumalanga, South Africa). From this table it can be seen that the work roll diameter and backup roll diameter is 505 and $1265 \mathrm{~mm}$, respectively. The work rollers are driven by a 110 $\mathrm{kW}$ asynchronous induction motor.

\section{Control process for the induction motor}

This section provides an overview on the control process for the induction motor with FOC and the schematics of the field-oriented controller. In the control process overview diagram of Figure 3, it can be seen that a three-phase diode rectifier supplies the dynamic braking chopper and DC bus capacitor. The dynamic braking chopper and DC bus capacitor absorbs the energy produced by the induction motor during deceleration.

The output of the braking chopper is connected to a three-phase PWM voltage source inverter, which supplies the induction motor. A speed controller uses the speed of the induction motor (measured by means of a speed sensor). The speed controller uses a $\mathrm{PI}$ controller to produce flux and torque references for the FOC unit. The thickness of the slab is measured by means of a position sensor. A transducer converts this signal to a reference speed.

The three reference line currents of the induction motor that corresponds with the flux and torque references are calculated by means of the FOC controller. The corresponding currents are then fed to the induction motor by means of a three-phase current regulator. For scenario 1 the speed reference is kept constant and a variable thickness slab is selected. For scenario 2 the speed is controlled according to the thickness of the slab.

For this project the three-phase diode rectifier, braking chopper, three-phase PWM inverter, FOC unit and speed controller was simulated by means of an AC3 block. The AC3 block models the FOC induction motor drive with the braking chopper for the motor (Blanchette and Dessaint, 2007).

The simulation model design was done by means of the SimPowerSystems ${ }^{\mathrm{TM}}$ library of Matlab $^{\circledR}$ Simulink $^{\circledR}$. An adapted model of Blanchette and Dessaint (2007) together with the parameters of Table 1 was used in the design process of the simulation model for this specific project.

Figure 4 provides the schematics on the FOC. In this controller, the phase angle of the rotor flux field is calculated by means of the phase calculation block and the change of the abc variables to dq components of the rotor flux field reference is done by means of the dq calculation block (Blanchette and Dessaint, 2007).

An estimation of the rotor flux of the induction motor is done by means of the rotor flux calculation block. Nait (1999) provides detail on direct FOC of induction motors with robust on-line tuning of the rotor resistance. The rotor flux reference, rotor flux and torque reference is used by the iqs* calculation block to calculate the stator current direct component necessary to generate the rotor flux in the induction motor and stator current quadrature component necessary to generate the torque on the rotor of the induction motor. De Doncker (1994) provides more detail on parameter sensitivity of indirect universal field-oriented controllers.

The change of the dq components to abc variables is done by means of the abc calculation block. The current is regulated by means of a current regulator with adjustable hysteresis bandwidth. The inverter commutation frequency is limited by means of a switching control block. Daboussi and Mohan (1988) provide more detail on digital simulation of FOC for induction motor drives. The flux dynamics is controlled by means of a flux controller. The conversion from the magnetization condition to the normal condition is done by means of the magnet control block (Blanchette and Dessaint, 2007). Novotny and Lipo (1996) provide more detail on vector control and dynamics of AC drives.

\section{RESULTS AND DISCUSSION}

This section provides the results obtained from the induction motor with DTC and FOC at the hot rolling mill. Results for the following two scenarios are presented: 1) where the induction motor was controlled at a constant speed with a variable thickness slab (DTC was used during this scenario), and 2) where the speed of the induction motor was controlled according to the thickness of the slab (FOC was used during this scenario). The energy consumption results for the simulation model as well as the experimental test setup system are presented.

\section{Simulation results - Scenario 1 (DTC)}

Figure 5 provides the performance results for scenario 1 , where the speed of the induction motor is constantly controlled at $150 \mathrm{rpm}$, irrespective of the thickness of the slab being processed. A variable thickness slab is selected and the rotor is given $0.2 \mathrm{~s}$ to start-up before a slab is processed. For this scenario, DTC was used. From Figure 5 it can be seen that the rotor speed drops 


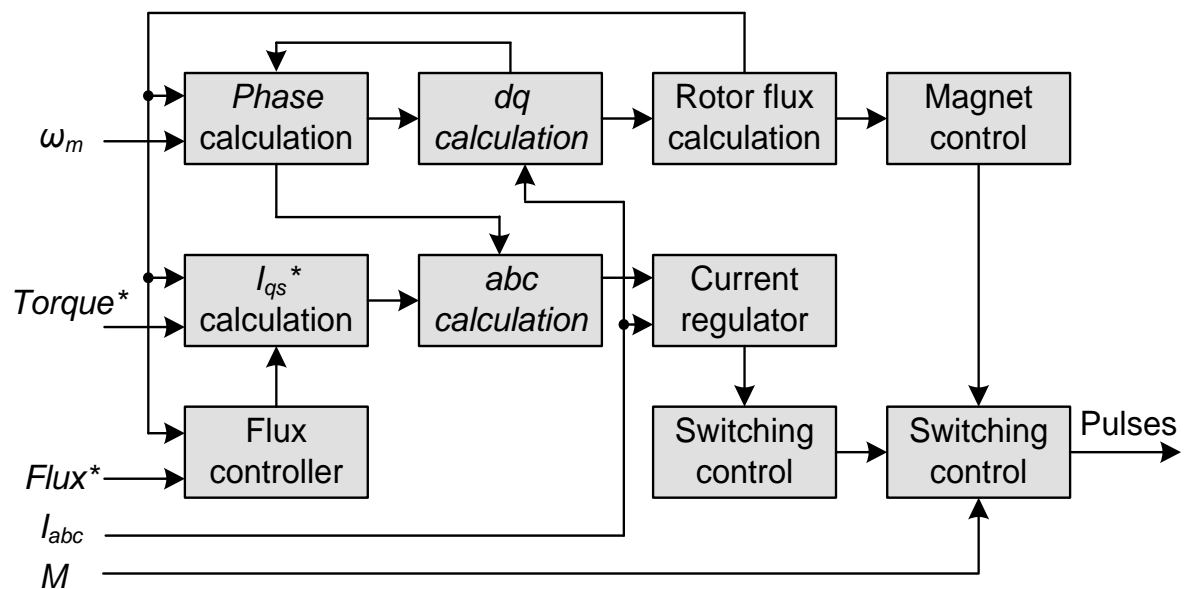

Figure 4. Field-oriented controller schematics.
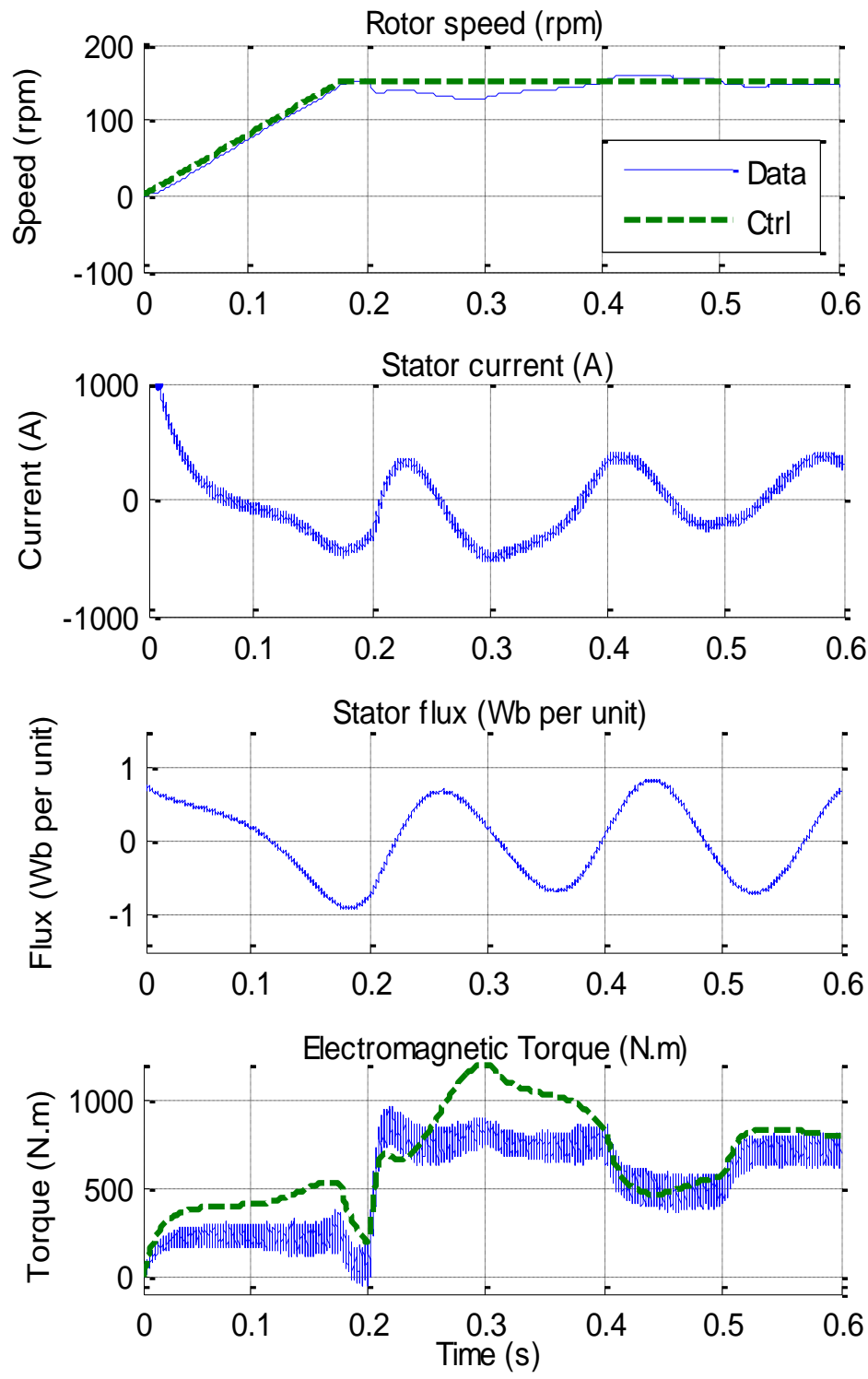

Figure 5. Scenario 1 - DTC model analysis. 
the moment the slab enters the process and the actual speed (Data) then closely follows the control speed (Ctrl). The actual electromagnetic torque (Data) closely follows the control torque (Ctrl). Figure 5 also shows the decoupling between the stator flux and the electromagnetic torque for scenario 1.

During startup, the current ramps up very high and the electromagnetic torque slowly increase to approximately $250 \mathrm{Nm}$. This is caused by the high initial start-up values chosen for the induction motor in the simulation parameters. The electromagnetic torque slowly increase, since the speed controller has been pre-programmed with user-defined maximum values during that period. At startup for scenario 1 and scenario 2 the rotor speed follows the control speed set-point of $150 \mathrm{rpm}$.

After $0.2 \mathrm{~s}$, the full load torque is applied to the rotor shaft while the rotor speed is still ramping to its final value. This forces the electromagnetic torque to increase to the user-defined maximum value of $1200 \mathrm{Nm}$ and then to stabilize at $800 \mathrm{Nm}$ once the rotor has reached 150 rpm and the speed ramping is completed. For scenario 1 the speed is then kept constant at $150 \mathrm{rpm}$, irrespective of the thickness of the slab.

\section{Simulation results - Scenario 2 (FOC)}

Figure 6 provides the performance results for scenario 2, where the speed of the induction motor is controlled according to the thickness of the slab being processed. The same variable thickness slab is selected for both scenarios. In this scenario, the rotor is again given $0.2 \mathrm{~s}$ to start-up before a slab is processed. For this scenario, FOC was used.

From this figure, it can be seen that the rotor speed drops slightly the moment the slab enters the process, but the speed is now controlled according to the thickness of the slab. The actual speed (Data) closely follows the control speed (Ctrl) and the actual electromagnetic torque (Data) closely follows the control torque (Ctrl). Figure 6 also shows the decoupling between the stator flux and the electromagnetic torque for scenario 2.

For scenario 2 between 0.2 and $0.6 \mathrm{~s}$, the control speed set point is changed according to the thickness of the slab. The speed decreases and increases by following the deceleration and acceleration ramps. During the whole simulation, the DC bus voltage is regulated to provide the expected output.

The reference frame of Figures 5 and 6 are different, since Figure 5 is for scenario 1 - DTC model analysis and Figure 6 is for scenario $2-$ FOC model analysis. The stator currents will therefore follow the provided reference frames for each specific model.

\section{Simulation results - Energy consumption}

Figure 7 provides the simulated energy consumption results for the two scenarios. In this figure, many spikes are visible in the active power profiles, which are caused by the switching of the three-phase PMW voltage source inverter. From the cumulative active power graph, it can be seen that during the first hour, the cumulative active power for scenario 2 is more than that of scenario 1 , but after $5 \mathrm{~h}$, the cumulative active power for scenario 2 is less than that of scenario 1 . The cumulative energy consumption for the simulated (ideal model) system resulted in an average improvement of $4.75 \%$ from scenario 1 to scenario 2 over the given time period.

\section{Experimental results - Energy consumption}

For the experimental test setup, the energy consumption of the induction motor of the hot rolling mill was captured and profiles were drawn. For the first set of data, the speed of the induction motor was constant controlled by means of DTC (scenario 1).

Variable thickness slabs were passed through the hot rolling mill and the energy consumption data were captured. For the second set of data, the speed of the induction motor was controlled according to the thickness of the slab. Slabs with the same thickness as in scenario 1 were selected, passed through the hot rolling mill and the energy consumption data were captured.

Figure 8 provides a representation of the energy consumption data for the experimental test setup. From this figure, it can be seen that the average energy demand profile for scenario 2 is lower than that of scenario 1. The average energy demand profile was calculated over a period of a few days, between 8:00 to 13:00 each day.

The total energy consumption for scenario 1 resulted in $920.14 \mathrm{kWh}$ and total energy consumption for scenario 2 resulted in $886.35 \mathrm{kWh}$ over the provided time period, which lead to a difference of $33.79 \mathrm{kWh}$. The system therefore resulted in an average energy consumption improvement of $3.67 \%$ from scenario 1 to scenario 2 over the provided time period.

\section{Conclusions}

In this paper, the results on the efficiency analysis of an induction motor with FOC at a hot rolling mill were presented. An overview on the control process and the schematics of the field-oriented controller for the induction motor were presented.

The results were divided into the following two scenarios: 1) where the induction motor was controlled at a constant speed with a variable thickness slab (DTC was used during this scenario) and 2) where the speed of the induction motor was controlled according to the thickness of the slab (FOC was used during this scenario). The results showed that the actual electromagnetic torque followed the control data more closely 

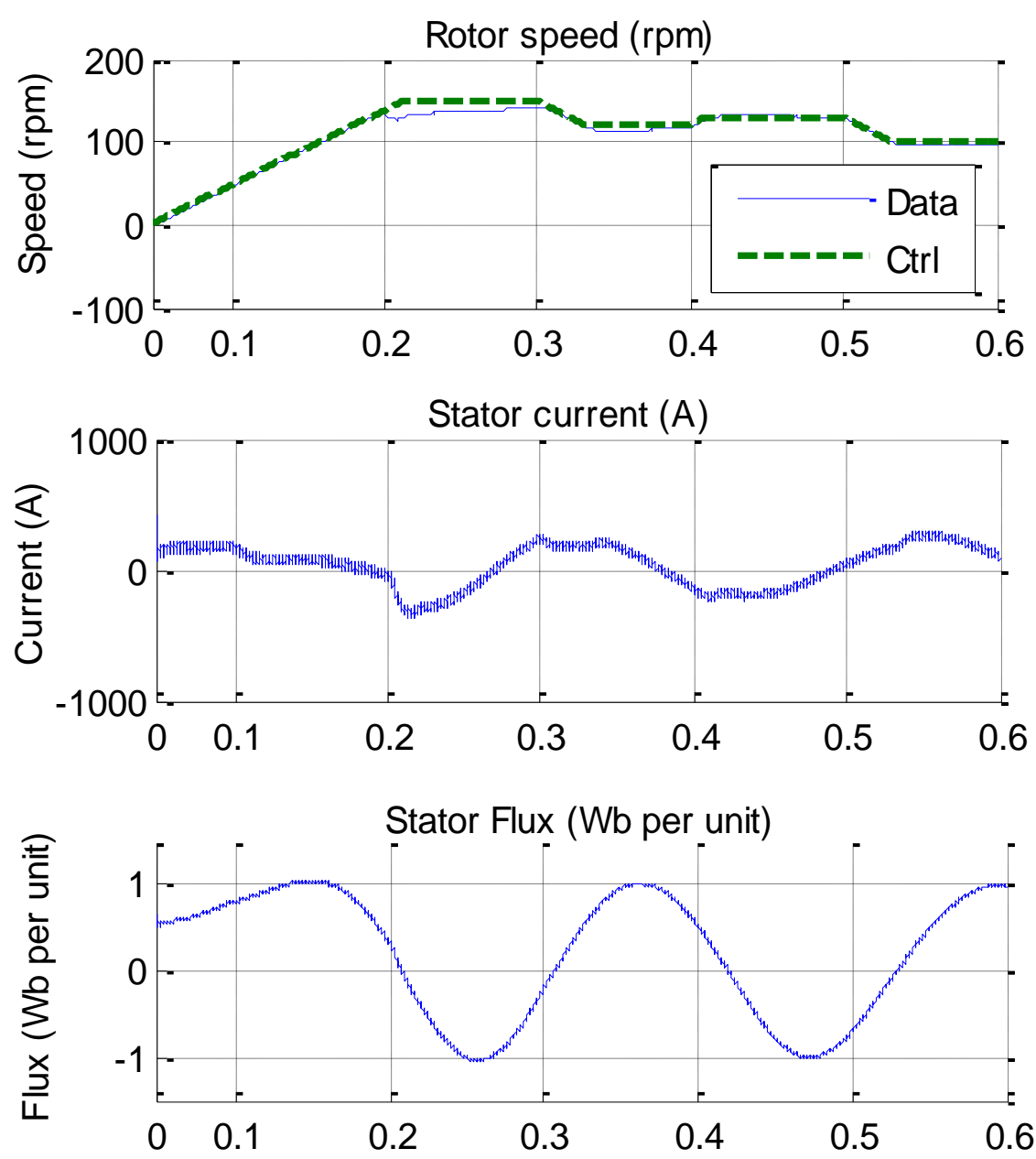

Electromagnetic Torque (N.m)

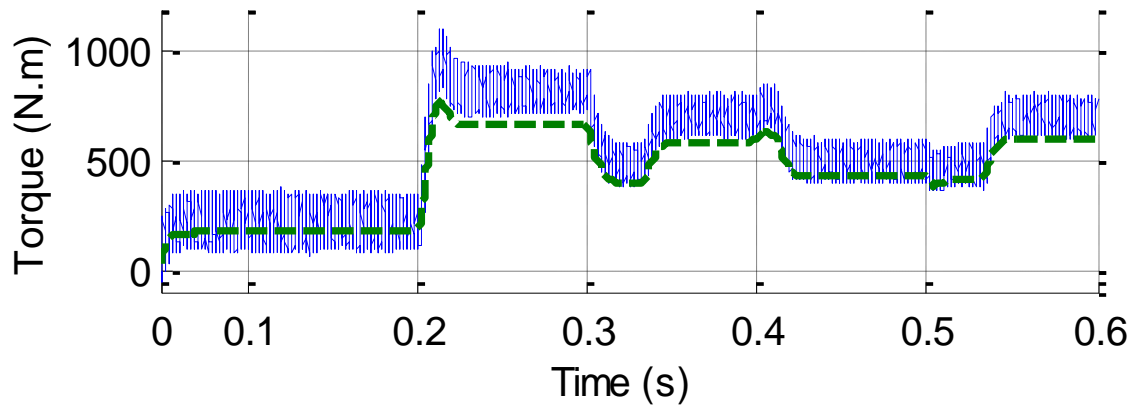

Figure 6. Scenario 2 - FOC model analysis.

for scenario 2 than for scenario 1 . The results for the cumulative active power showed that for the first hour the cumulative active power for scenario 2 is more than that of scenario 1, but after $5 \mathrm{~h}$ the cumulative active power for scenario 2 is less than that of scenario 1. The simulation results showed an average improvement of $4.75 \%$ in the cumulative energy consumption from scenario 1 to scenario 2 over the provided time period.

The experimental results showed an average improvement of $3.67 \%$ from scenario 1 to scenario 2 over the provided time period. A difference in the improvement values is expected, since the simulation model is an ideal case model. Environmental conditions and age of the induction motor have also not been taken into account with the simulation model. Pedersen (1998) and Wu (2006), present more detail on multivariable controller design for a hot rolling mill, and high-power converters and $\mathrm{AC}$ drives. 

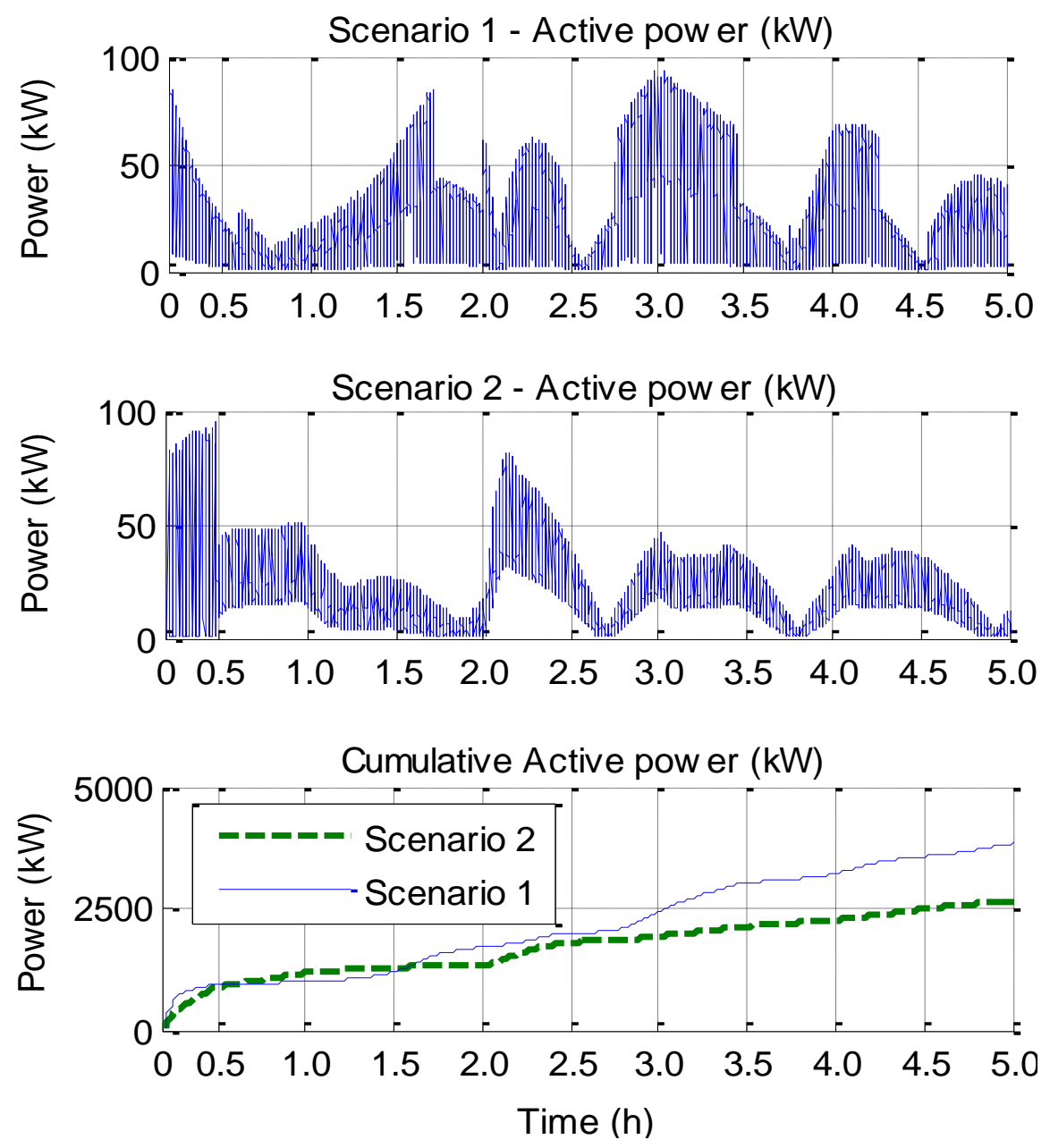

Figure 7. Simulated energy consumption.

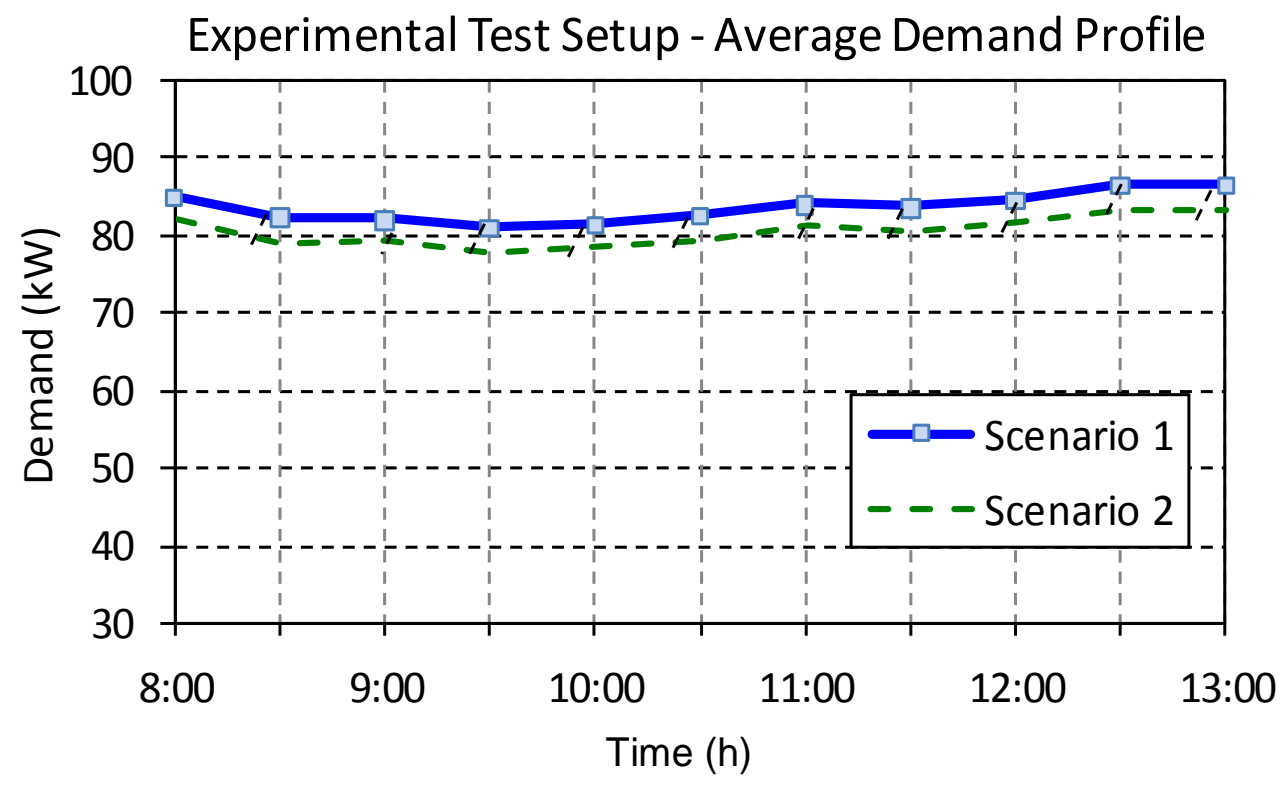

Figure 8. Experimental test setup - energy consumption. 


\section{REFERENCES}

Achenbach B (2002). Aluminium rolling mill technology. Bib. Tech. 1(1):233-234.

Blanchette H, Dessaint LA (2007). AC3 - FOC induction $200 \mathrm{hp}$ motor drive. E. Tech. Sup. 1(1):1-10.

Daboussi Z, Mohan N (1988). Digital simulation of field-oriented control of induction motor drives using EMTP. IEEE Trans. Energy Conversion 3(3):667-673.

De Doncker RW (1994). Parameter sensitivity of indirect universal fieldoriented controllers, IEEE Trans. Pow. Elect. 9(4):367-376.

DME (1998). White paper on the energy policy of the Republic of South Africa (RSA), Dept. Minerals Energy, pp.1-15.

Gouws R (2011). Efficiency analysis of an induction motor with direct torque and flux control at a hot rolling mill, Proc. Int. ICUE Conf. 11:63-68.

Islam FMR (2010). Field oriented control of IPMSM. Lamb. Acad. Pub. pp. 51-89.
Kubota H (1994). Speed sensor-less field-oriented control of induction motor with rotor resistance adaptation. IEEE Trans. Ind. Appl. 30(5):1219-1224.

Lenard JG (2007). Primer on flat rolling. Els. Sci. 25-53.

Nait MS (1999). Induction motors direct field oriented control with robust on-line tuning of rotor resistance, IEEE Trans. Energy Conversion 14(4):1038-1042.

Novotny DW, Lipo TA (1996). Vector control and dynamics of AC drives, Ox. Univ. Pr. 151-196.

Pedersen LM (1998). Multivariable controller design for a hot rolling mill, IEEE Trans. Cont. Syst. Tech. 6(2):304-312.

Pittner J, Simaan MA (2011). Tandem cold metal rolling mill control using practical advanced methods, Spring. Ver. pp.1-19.

Wu B (2006). High-power converters and AC drives, IEEE Pr., WileyIntersci. pp. 285-319. 